\title{
Impact of metabolically healthy obesity on the risk of incident gastric cancer: a population-based cohort study
}

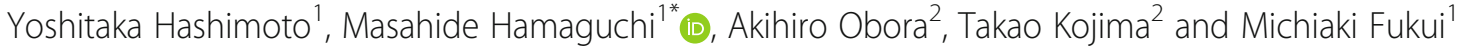

\begin{abstract}
Background: The risk of colon or breast cancer in metabolically healthy obese $(\mathrm{MHO})$ were lower than that in metabolically abnormal obese (MAO). We hypothesized that the risk of incident gastric cancer in $\mathrm{MHO}$ is lower than that in MAO.

Methods: This historical cohort study included 19,685 Japanese individuals who received health-checkup programs from 2003 to 2016. Each subject was classified as metabolically healthy (MH) (no metabolic abnormalities) or metabolically abnormal (MA) (one or more metabolic abnormalities), according to four metabolic factors (hypertension, impaired fasting glucose, hypertriglyceridemia and low HDL-cholesterol). Obese $(\mathrm{O})$ or non-obese (NO) was classified by a BMl cutoff of $25.0 \mathrm{~kg} / \mathrm{m}^{2}$. Hazard ratios of metabolic phenotypes for incident gastric cancer were calculated by the Cox proportional hazard model with adjustments for age, sex, alcohol consumption, smoking and exercise.

Results: Over the median follow-up period of 5.5 (2.9-9.4) years, incident rate of gastric cancer was 0.65 per 1000 persons-years. Incident rate of MHNO, MHO, MANO and MAO were $0.33,0.25,0.80$ and 1.21 per 1000 persons-years, respectively. Compared with $\mathrm{MHNO}$, the adjusted hazard ratios for development of gastric cancer were $0.69(95 \% \mathrm{Cl}$ $0.04-3.39, p=0.723)$ in $\mathrm{MHO}, 1.16(95 \% \mathrm{Cl} 0.63-2.12, p=0.636)$ in MANO and $2.09(95 \% \mathrm{Cl} 1.10-3.97, p=0.024)$ in MAO.

Conclusions: This study shows that individuals with $\mathrm{MAO}$, but not those with $\mathrm{MHO}$, had an elevated risk for incident gastric cancer. Thus, we should focus more on the presence of metabolic abnormalities rather than obesity itself for incident gastric cancer.
\end{abstract}

Keywords: Obesity, Metabolically healthy obesity, Metabolic syndrome, Cancer, Gastric cancer

\section{Background}

Gastric cancer is a major global health concern and was the third leading cause of cancer death worldwide in 2012 [1] and gastric cancer is the third leading cause of cancer death in 2016 in Japan [2]. Previous meta-analyses showed that obesity was a risk factor for incident gastric cancer, especially gastric cardia cancer [3], although an umbrella review revealed the effect of obesity on gastric cancer was smaller than that on other obesity-related cancers, such as colon and breast cancers [4].

\footnotetext{
* Correspondence: mhama@koto.kpu-m.ac.jp

${ }^{1}$ Department of Endocrinology and Metabolism, Kyoto Prefectural University of Medicine, Graduate School of Medical Science, 465 Kajii-cho,

Kawaramachi-Hirokoji, Kamigyo-ku, Kyoto 602-8566, Japan

Full list of author information is available at the end of the article
}

On the other hand, obesity is also known as a risk factor for type 2 diabetes mellitus (T2DM) [5], chronic kidney disease (CKD) [6] and cardiovascular disease (CVD) [7]. The subgroup of individuals with metabolically healthy obesity (MHO)-i.e., obesity without metabolic abnormalities-are knowns as lower risk of T2DM, CKD and CVD than individuals with metabolic abnormalities obese [8-11]. However, these studies also revealed that individuals with the MHO phenotype were at higher risk of T2DM, CKD and CVD than individuals with metabolically healthy non-obese $[8,10,11]$. In addition, there is accumulating evidence that metabolically abnormal obesity (MAO), but not MHO, confers an elevated risk of incident colon cancer [12] and breast cancer [13]. The

(C) The Author(s). 2020 Open Access This article is distributed under the terms of the Creative Commons Attribution 4.0 International License (http://creativecommons.org/licenses/by/4.0/), which permits unrestricted use, distribution, and 
association between gastric cancer and obesity among Japanese population is controversial [14, 15]. These studies did not consider the presence of metabolic abnormalities. In contrast, there is an association between metabolic syndrome and incidence of gastric cancer [16-19]. Thus, we thought that not obesity itself, but the presence of metabolic abnormalities, which often accompany with obesity, have an important meaning for gastric cancer.

To our knowledge, however, no previous studies have clarified the relation between $\mathrm{MHO}$ and incident gastric cancer. Thus, the aim of this study was to elucidate the impact of $\mathrm{MHO}$ on incident gastric cancer.

\section{Methods}

\section{Study population}

This was an historical cohort study of participants who received a medical health-checkup at Asahi University Hospital (the NAGALA (NAfld in Gifu Area, Longitudinal Analysis) study, Gifu, Japan) [20]. The purpose of medical health-checkup was to promote public health by early detection of chronic diseases and their risk factors and about $60-70 \%$ examiners received the examinations, repeatedly; thus, the participants represent apparently healthy individuals. Most of the participants of this medical health-checkup were employees of various companies and local governmental organizations in Gifu, Japan, and their consorts. The medical data of all individuals who agreed to participate in the study were stored in a database after removing all personally identifiable information. For the current study, we used the results of individuals who participated in the health-checkup program for at least one year between 2003 and 2016. The exclusion criteria of this study were as follows: the presence of gastric cancer at baseline examination, missing covariate data (body weight, high-density lipoprotein (HDL) cholesterol, and lifestyle factors) and no followup health-checkup programs. Informed consent was obtained from each participant. The study was approved by the ethics committee of Murakami Memorial Hospital and was conducted in accordance with the Declaration of Helsinki.

\section{Data collection}

A self-administered questionnaire was used for gathering the medical history and lifestyle factors of participants [20]. In regard to alcohol consumption, participants were asked the type and amounts of alcoholic beverages consumed per week over the past month, and then the mean ethanol intake per week was estimated [21]. For smoking status, the participants were categorized into three groups: never-, ex- and current smokers. In addition, smoking burden was evaluated by pack-years which were calculated by multiplying the number of cigarette packs smoked per day by the number of years of smoking [22]. For exercise, participants were asked to describe the type, duration and frequency of sports or recreational activities [23]. Based on the results, we defined regular exercisers as the participants who performed any kind of sports activity at least once a week on a regular basis [21]. Body mass index (BMI) $\left(\mathrm{kg} / \mathrm{m}^{2}\right)$ was calculated as body weight $(\mathrm{kg})$ divided by height $(\mathrm{m})$ squared. Waist circumference was measured as the abdominal circumference around the navel. Fasting plasma glucose, triglycerides, or HDL cholesterol was measured using the venous blood after an overnight fast. The methods for detecting and diagnosing gastrointestinal cancers were described previously [24]. Because the first standardized questionnaires for gastrointestinal cancers were sent on Jan 1st 2003, we set the study period as Jan 1st 2003 to Dec 31st 2016. The primary endpoint of this study was hazard risk (HR) of MHO for gastric cancer.

\section{Definitions of metabolic phenotypes}

We used body mass index $\geq 25.0 \mathrm{~kg} / \mathrm{m}^{2}$ to identify the individual with obesity. This value has been proposed as a cutoff for the diagnosis of individual with obesity in Asian people [25] and has often been used in Japan [26, 27]. Four metabolic factors (fasting plasma glucose, triglycerides, HDL cholesterol and blood pressure) were used to divide participants into metabolically healthy or metabolically abnormal subgroups [9]. Impaired fasting plasma glucose and/or diabetes was defined as fasting plasma glucose $\geq 5.6 \mathrm{mmol} / \mathrm{L}$ and/or current medical treatment. Hypertension was defined as systolic blood pressure $>130$ $\mathrm{mmHg}$ and/or diastolic blood pressure $\geq 85 \mathrm{mmH}$ or current medical treatment. Elevated triglycerides were defined as triglycerides $\geq 1.7 \mathrm{mmol} / \mathrm{L}$ or treatment for hyperlipidemia. Low HDL-cholesterol was defined as $<1.0$ $\mathrm{mmol} / \mathrm{L}$ in men and $<1.3 \mathrm{mmol} / \mathrm{L}$ in women. When none of these four metabolic factors were present, we defined the participants as metabolically healthy $(\mathrm{MH})$ and when one or more of these four metabolic factors were present, we defined the participants as metabolically abnormal (MA) [28]. Then, participants were categorized at the baseline examination into 4 phenotypes: metabolically healthy non-obesity (MHNO), metabolically healthy obesity (MHO); metabolically abnormal non-obesity (MANO), and metabolically abnormal obesity (MAO).

\section{Statistical analysis}

The study participants were divided into four groups based on metabolic phenotypes. Continuous variables were expressed as the means \pm standard deviation or median (interquartile range) and categorical variables were expressed as numbers. The clinical characteristics at baseline examination of the four groups were compared; continuous variables of groups were evaluated by one-way ANOVA and Tukey's Honestly Significant Difference Test 
or Kruskal-Wallis Test and Steel-Dwass Test, and categorical variables of groups were evaluated by Pearson's ChiSquared Test. Because of the censored cases and inconsistent follow-up duration, we used the Cox Proportional Hazards Model to calculate the HR of the four groups. We considered five potential confounders as covariates: age, sex, alcohol consumption [29], pack-years [30], and exercise [31]. Because alcohol consumption and pack-years were skewed variables, logarithmic transformation was carried out before performing the Cox Proportional Hazard Model analysis.

Furthermore, we used the Cox Proportional Hazards Model to calculate the HR of each metabolic abnormality (hypertension, impaired fasting glucose, hypertriglyceridemia and low HDL-cholesterol).

The statistical analyses were performed using JMP version 13.2 software (SAS Institute Inc., Cary, NC). A $p$ value $<0.05$ was considered statistically significant.

\section{Results}

We included 27,944 participants from the NAGALA database (Fig. 1). Among them, 8259 participants were excluded. Thus, 19,685 participants were eligible for this cohort study. The baseline characteristics of the participants are shown in Table 1. Average age and BMI of this study participants were $45.5 \pm 9.5$ years old and $22.6 \pm$ $3.3 \mathrm{~kg} / \mathrm{m}^{2}$ and $59.9 \%(11,782)$ were men. In addition, both BMI and metabolic parameters, including blood pressure, fasting plasma glucose, triglycerides and HDL cholesterol, were different among the four metabolic phenotype groups.

Over the median follow-up period of 5.5 (2.9-9.4) years, incident rate of gastric cancer was 0.65 per 1000 persons-years. Incident rate of MHNO, MHO, MANO and MAO were $0.33,0.25,0.80$ and 1.21 per 1000 persons-years, respectively.

The results of the Cox proportional hazard model are shown in Table 2 and Additional file 1: Table S1. Compared with the MHNO phenotype, the MAO phenotype (adjusted HR 2.09, 95\%CI 1.10-3.97, $p=0.024$ ) was associated with a higher risk for development of gastric cancer after adjusting for covariates, whereas the MHO phenotype (adjusted HR 0.69, 95\%CI 0.04-3.39, $p=0.723$ ) was not.

Furthermore, presence of impaired fasting plasma glucose and/or diabetes, hypertension and elevated triglycerides were associated with incident gastric cancer (Table 3).

\section{Discussion}

This cohort study of apparently healthy Japanese people is the first to reveal an association between MHO and incident gastric cancer. This study shows that individuals with MAO, but not those with MHO, had an elevated risk for incident gastric cancer. In addition, the presence of impaired fasting plasma glucose and/or diabetes, and hypertension were associated with elevated risk incident gastric cancer.

Obesity was a risk factor for incident gastric cancer [3], although the effect of obesity on gastric cancer was smaller than that on other obesity-related cancers. Previous studies revealed that the risk of incident colorectal cancer [12] and incident breast cancer [13], both of which have been shown to be related to obesity [4], was not high in subjects with MHO. In addition, another study revealed that the risk of obesity-related cancer in $\mathrm{MHO}$ was lower than that in MAO [32]. In fact, previous studies revealed the association between metabolic syndrome and incidence of gastric cancer [16-19].

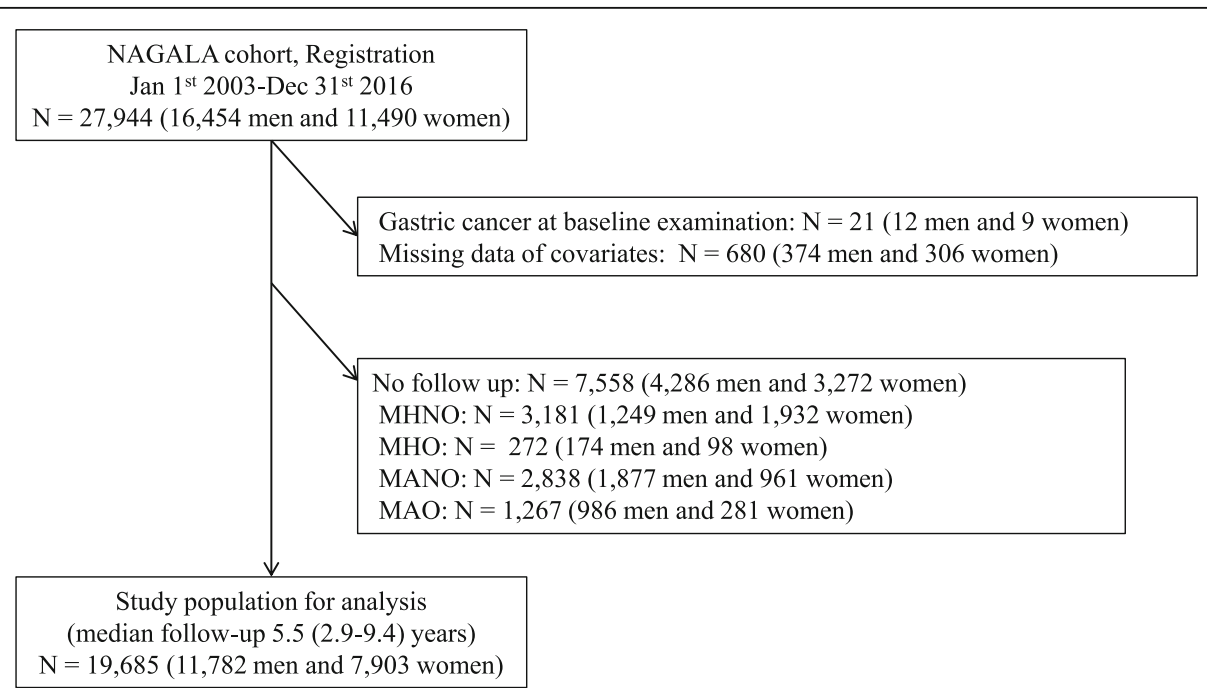

Fig. 1 Inclusion and exclusion flow chart. NAGALA, NAfld in Gifu Area, Longitudinal Analysis; MHNO, Metabolically healthy non-obesity; MHO, Metabolically healthy obesity; MANO, Metabolically abnormal non-obesity; MAO, Metabolically abnormal obesity 
Table 1 Characteristics of study participants at the baseline examination

\begin{tabular}{|c|c|c|c|c|c|c|}
\hline & All & MHNO & $\mathrm{MHO}$ & MANO & MAO & $p$ \\
\hline $\mathrm{N}$ & 19,685 & 8331 & 653 & 7276 & 3425 & - \\
\hline Age, years (mean $\pm \mathrm{SD}$ ) & $45.5 \pm 9.5$ & $42.6 \pm 8.7$ & $43.8 \pm 8.3 *$ & $48.3 \pm 9.7 *+$ & $47.0 \pm 9.0 * 十 \neq$ & $<0.001$ \\
\hline Men, \% (n) & $59.9 \%(11,782)$ & $42.0 \%(3496)$ & $424 / 229$ & $5088 / 2188$ & $2774 / 651$ & $<0.001$ \\
\hline $\mathrm{BMI}, \mathrm{kg} / \mathrm{m}^{2}($ mean $\pm \mathrm{SD})$ & $22.6 \pm 3.3$ & $20.7 \pm 2.1$ & $26.7 \pm 1.7 *$ & $22.1 \pm 1.9 *+$ & $27.6 \pm 2.5 * \dagger \neq$ & $<0.001$ \\
\hline Waist circumference, $\mathrm{cm}$ (mean \pm SD) & $78.0 \pm 9.6$ & $72.3 \pm 7.0$ & $86.9 \pm 6.0 *$ & $77.9 \pm 6.8 *+$ & $90.6 \pm 7.2 *+\neq$ & $<0.001$ \\
\hline $\mathrm{SBP}, \mathrm{mmHg}($ mean $\pm \mathrm{SD})$ & $117.5 \pm 16.3$ & $108.0 \pm 10.7$ & $116.1 \pm 8.9 *$ & $122.2 \pm 16.2 *+$ & $130.8 \pm 15.2 *$ *† & $<0.001$ \\
\hline $\mathrm{DBP}, \mathrm{mmHg}($ mean $\pm \mathrm{SD})$ & $73.7 \pm 11.2$ & $67.2 \pm 7.8$ & $72.6 \pm 6.7 *$ & $76.9 \pm 11.0 *+$ & $82.6 \pm 10.1 *+\neq$ & $<0.001$ \\
\hline $\mathrm{FPG}, \mathrm{mmol} / \mathrm{L}($ mean $\pm \mathrm{SD})$ & $5.4 \pm 0.9$ & $5.0 \pm 0.3$ & $5.1 \pm 0.3 *$ & $5.6 \pm 1.0 *+$ & $6.0 \pm 1.3 * \dagger \neq$ & $<0.001$ \\
\hline Triglycerides, mmol/L (median (interquartile range)) & $0.8(0.5-1.2)$ & $0.6(0.4-0.8)$ & $0.8(0.6-1.2) *$ & $1.0(0.6-1.5) *+$ & $1.3(0.9-1.9) *+\neq$ & $<0.001$ \\
\hline $\mathrm{HDL}$ cholesterol, mmol/L (mean $\pm \mathrm{SD})$ & $1.4 \pm 0.4$ & $1.6 \pm 0.4$ & $1.4 \pm 0.3 *$ & $1.3 \pm 0.4 *+$ & $1.2 \pm 0.3 *+\neq$ & $<0.001$ \\
\hline Exercise & $16,111 / 3574$ & $81.4 \%(6781)$ & $540 / 113$ & $5911 / 1365$ & $2879 / 546$ & 0.002 \\
\hline Smoking status & & & & & & $<0.001$ \\
\hline Never- smoker, \% (n) & $53.2 \%(10,480)$ & $65.0 \%(5414)$ & $53.0 \%(346)$ & $45.9 \%(3342)$ & $40.2 \%(1378)$ & \\
\hline Ex-smoker, \% (n) & $22.4 \%(4405)$ & $16.0 \%(1331)$ & $23.4 \%(153)$ & $26.1 \%(1897)$ & $29.9 \%(1024)$ & \\
\hline Current smoker, \% (n) & $24.3 \%(4776)$ & $16.5 \%(1375)$ & $23.6 \%(154)$ & $27.9 \%(2029)$ & $29.7 \%(1018)$ & \\
\hline Smoking burden, pack-years (median (interquartile range)) & $0(0-305)$ & $0(0-120)$ & $0(0-300) *$ & $50(0-420) *+$ & $150(0-460) *+\ddagger$ & $<0.001$ \\
\hline Alcohol consumption, g/wk. (median (interquartile range)) & $4.2(0-90)$ & $1(0-54)$ & $1(0-66) *$ & $12(0-126) *+$ & $12(1-126) *+$ & 0.070 \\
\hline
\end{tabular}

As to why MAO, but not $\mathrm{MHO}$, was associated with a higher risk of incident gastric cancer, there were several possible explanations. It has been reported that metabolic syndrome is associated with gastric cancer [16-19]. In this study, we showed that the presence of metabolic abnormalities, especially impaired fasting plasma glucose and/or diabetes and hypertension, were associated with gastric cancer, which was same as previous studies [33, 34]. Inflammation, as represented by elevation of the pro-inflammatory cytokines tumor necrosis factor- $\alpha$ (TNF- $\alpha$ ), interleukin-6 (IL-6), and monocyte chemoattractant protein-1 (MCP-1), is known to be closely associated with not only obesity [35], but also the metabolic abnormalties, including impaired fasting plasma glucose and hypertension [36]. Inflammation leads to the development of gastric cancer by stimulating proliferation and inhibiting apoptosis of human gastric cancer cells [37]. Formation of reactive oxygen species (ROS), by formation of advanced glycation end products [38], leads to DNA damage and development of gastric cancer. In addition, tumor cell progression is stimulated by enhancing the mTOR signaling pathways through an increase in insulin-like growth factor 1 (IGF-1) [39]. On the other hand, it has been reported that the levels of inflammation and IGF-1 in MHO were lower than those in MAO [40, 41]. Collectively, these results could explain why the MAO phenotype, but not the MHO phenotype, was associated with a higher risk of incident gastric cancer.

Table 2 Hazard ratio of metabolic phenotype for incident gastric cancer

\begin{tabular}{lllll}
\hline & MHNO & MHO & MANO & MAO \\
\hline Person-year, $\mathrm{n}$ & $51,846.1$ & 3949.65 & $44,011.9$ & $20,583.1$ \\
Incident cases, $\mathrm{n}$ & 17 & 1 & 35 & 25 \\
Incidence rate per 1000 person-years & 0.33 & 0.25 & 0.80 & 1.21 \\
Crude model & Ref & $0.77(0.04-3.77), p=0.797$ & $2.43(1.38-4.45), p=0.002$ & $3.72(2.02-7.00), p<0.001$ \\
Model 1 & Ref & $0.68(0.04-3.32), p=0.691$ & $1.19(0.66-2.23), p=0.567$ & $2.16(1.14-4.09), p=0.018$ \\
Model 2 & Ref & $0.69(0.04-3.39), p=0.723$ & $1.16(0.63-2.12), p=0.636$ & $2.09(1.10-3.97), p=0.024$ \\
\hline
\end{tabular}

MHNO Metabolically healthy non-obesity; $\mathrm{MHO}$ Metabolically healthy obesity; MANO Metabolically abnormal non-obesity; MAO Metabolically abnormal obesity; $\mathrm{Cl}$ Confidence interval; Log logarithmic. Model 1 was adjusted for age and sex. Model 2 was adjusted for age, sex, exercise habit, log (alcohol consumption +1$)$ and $\log ($ pack-year +1$)$ 
Table 3 Hazard ratio of each metabolic phenotype for incident gastric cancer

\begin{tabular}{|c|c|c|}
\hline & $\begin{array}{l}\text { Impaired fasting plasma glucose } \\
\text { and/or diabetes }(-)\end{array}$ & $\begin{array}{l}\text { Impaired fasting plasma glucose } \\
\text { and/or diabetes }(+)\end{array}$ \\
\hline Person-year, n & $85,934.94$ & $34,455.79$ \\
\hline Incident cases, n & 38 & 40 \\
\hline Incidence rate per 1000 person-years & 0.44 & 1.16 \\
\hline \multirow[t]{2}{*}{ Crude model } & Ref & $2.67(1.71-4.17), p<0.001$ \\
\hline & Hypertension (-) & Hypertension (+) \\
\hline Person-year, n & $91,735.7$ & 28,655 \\
\hline Incident cases, n & 46 & 32 \\
\hline Incidence rate per 1000 person-years & 0.50 & 1.12 \\
\hline \multirow[t]{2}{*}{ Crude model } & Ref & $2.28(1.44-3.56), p<0.001$ \\
\hline & Elevated triglycerides (-) & Elevated triglycerides (+) \\
\hline Person-year, n & 104,572 & $15,818.4$ \\
\hline Incident cases, n & 62 & 16 \\
\hline Incidence rate per 1000 person-years & 0.59 & 1.01 \\
\hline \multirow[t]{2}{*}{ Crude model } & Ref & $1.69(0.94-2.85), p=0.077$ \\
\hline & Low HDL-cholesterol (-) & Low HDL-cholesterol (+) \\
\hline Person-year, n & $93,354.8$ & 27,036 \\
\hline Incident cases, n & 55 & 23 \\
\hline Incidence rate per 1000 person-years & 0.59 & 0.86 \\
\hline Crude model & Ref & $1.41(0.85-2.26), p=0.180$ \\
\hline
\end{tabular}

HDL High-density lipoprotein

Some limitations of our study should be noted. First, there was a possibility of selection bias, because we only included the participants who were re-examined in the health-checkup program. There is a possibility that there is a characteristic difference between the participants who were re-examined in the health-checkup program and those who did not. Second, we did not have data on H. pylori infection, which is known to pose a risk for gastric cancer [42]. In fact, many Japanese, especially elderly people, are infected with $H$. pylori [43]. Therefore, the results of this study might have been affected by the status of $H$. pylori infection. Third, we did not have detailed data on gastric cancer according to the anatomic location of the lesion, such as gastric noncardia cancer and gastric cardia cancer. A previous study revealed that gastric cardia cancer showed a greater association with obesity than non-cardia cancer [1]. Lastly, the generalizability of our study to non-Japanese populations is uncertain.

\section{Conclusion}

In conclusion, our study showed that MAO individuals, not but MHO individuals, had a higher risk of incident gastric cancer. Thus, to prevent future gastric cancer, we should focus more on the presence of metabolic abnormalities rather than obesity itself.

\section{Supplementary information}

Supplementary information accompanies this paper at https://doi.org/10. 1186/s12902-019-0472-2.

Additional file 1: Table S1. Hazard ratio of potential confounders for

incident gastric cancer.

\section{Abbreviations}

BMI: Body mass index; CKD: Chronic kidney disease; CVD: Cardiovascular disease; HDL: High-density lipoprotein; HR: Hazard ratio; IGF-1: Insulin-like growth factor 1; IL-6: Interleukin-6; MANO: Metabolically abnormal nonobesity; MAO: Metabolically abnormal obesity; MCP-1: Monocyte chemoattractant protein-1; MHNO: Metabolically healthy non-obesity; $\mathrm{MHO}$ : Metabolically healthy obesity; ROS: Reactive oxygen species; T2DM: Type 2 diabetes mellitus; TNF-a: Tumor necrosis factor-a

\section{Acknowledgments}

We thank all the staff members at the medical health checkup center at Asahi University Hospital.

\section{Authors' contributions}

Y.H. designed the study, analyzed and interpreted the data, and wrote the manuscript. M.H. originated the study, researched and interpreted the data, and reviewed and edited the manuscript. A.O. and T.K. originated the study, researched the data and reviewed the manuscript. M.F. designed the study, interpreted the data, and reviewed the manuscript. M.H. is the guarantor of this work and, as such, had full access to all the data in the study and takes responsibility for the integrity of the data and the accuracy of the data analysis. All authors have approved the final draft submitted.

Funding

No funding was obtained for this study. 


\section{Availability of data and materials}

The datasets generated during and/or analyzed during the current study are available from the corresponding author on reasonable request.

\section{Ethics approval and consent to participate}

Written informed consent was obtained from each participant. The study was approved by the ethics committee of Murakami Memorial Hospital.

\section{Consent for publication}

Not applicable.

\section{Competing interests}

None. Potential conflict of interest was follows; Y.H. received grants from the Japan Society for the Promotion of Science, and Asahi Kasei Pharma outside the submitted work. M.F. received grants from the Japan Society for the Promotion of Science, AstraZeneca Plc, Astellas Pharma Inc., Nippon Boehringer Ingelheim Co., Ltd., Daiichi Sankyo Co., Ltd., Eli Lilly Japan K.K., Kyowa Hakko Kirin Company, Ltd., Kissei Pharmaceutical Co., Ltd., MSD K.K., Mitsubishi Tanabe Pharma Corporation, Novo Nordisk Pharma, Ltd., Sanwa Kagaku Kenkyusho Co., Ltd., Sanofi K.K., Ono Pharmaceutical Co., Ltd., and Takeda Pharmaceutical Co., Ltd., outside the submitted work. The sponsors were not involved in the study design; in the collection, analysis, or interpretation of data; in the writing of this manuscript; or in the decision to submit the article for publication. The authors, their immediate families, and any research foundations with which they are affiliated have not received any financial payments or other benefits from any commercial entity related to the subject of this article. The above authors declare that although they are affiliated with a department that is supported financially by a pharmaceutical company, they have received no funding for this study, and their affiliation does not alter their adherence to all the journal policies on sharing data and materials. The other authors have nothing to disclose.

\section{Author details}

'Department of Endocrinology and Metabolism, Kyoto Prefectural University of Medicine, Graduate School of Medical Science, 465 Kajii-cho, Kawaramachi-Hirokoji, Kamigyo-ku, Kyoto 602-8566, Japan. ${ }^{2}$ Department of Gastroenterology, Asahi University Hospital, Gifu, Japan.

Received: 15 June 2019 Accepted: 10 December 2019

\section{Published online: 20 January 2020}

\section{References}

1. Upala S, Jaruvongvanich $V$, Riangwiwat $T$, et al. Association between helicobacter pylori infection and metabolic syndrome: a systematic review and meta-analysis. J Dig Dis. 2016;17:433-40. https://doi.org/10.1111/17512980.12367.

2. Vital Statistics Japan. Deaths and Mortality. Ministry of Health, Labour and Welfare. http://www.mhlw.go.jp/toukei/saikin/hw/jinkou/kakutei16/dl/11_h7. pdf (in Japanese). Available on 24 Feb, 2018.

3. Lin XJ, Wang CP, Liu XD, et al. Body mass index and risk of gastric cancer: a meta-analysis. Jpn J Clin Oncol. 2014:44:783-91. https://doi.org/10.1093/jjco/ hyu082.

4. Kyrgiou M, Kalliala I, Markozannes G, et al. Adiposity and cancer at major anatomical sites: umbrella review of the literature. BMJ. 2017;356:j477. https://doi.org/10.1136/bmj.j477.

5. Mitsuhashi $K$, Hashimoto $Y$, Tanaka M, et al. Combined effect of body mass index and waist-height ratio on incident diabetes; a population based cohort study. J Clin Biochem Nutr. 2017;61:118-22. https://doi.org/10.3164/ jcbn.16-116.

6. Garofalo C, Borrelli S, Minutolo R, et al. A systematic review and metaanalysis suggests obesity predicts onset of chronic kidney disease in the general population. Kidney Int. 2017;91:1224-35. https://doi.org/10.1016/j. kint.2016.12.013.

7. Arnlöv J, Ingelsson E, Sundström J, et al. Impact of body mass index and the metabolic syndrome on the risk of cardiovascular disease and death in middle-aged men. Circulation. 2010;121:230-6. https://doi.org/10.1161/ CIRCULATIONAHA.109.887521.

8. Bell JA, Kivimaki M, Hamer M. Metabolically healthy obesity and risk of incident type 2 diabetes: a meta-analysis of prospective cohort studies. Obes Rev. 2014;15:504-15. https://doi.org/10.1111/obr.12157.
9. Hashimoto $\mathrm{Y}$, Tanaka M, Okada H, et al. Metabolically healthy obesity and risk of incident CKD. Clin J Am Soc Nephrol. 2015;10:578-83. https://doi.org/ 10.2215/CJN.08980914

10. Kramer CK, Zinman B, Retnakaran R. Are metabolically healthy overweight and obesity benign conditions?: a systematic review and meta-analysis. Ann Intern Med. 2013;159:758-69. https://doi.org/10.7326/0003-4819-159-11201312030-00008.

11. Zhang J, Jiang $H$, Chen J. Combined effect of body mass index and metabolic status on the risk of prevalent and incident chronic kidney disease: a systematic review and meta-analysis. Oncotarget. 2017:8:3561929. https://doi.org/10.18632/oncotarget.10915.

12. Murphy N, Cross AJ, Abubakar M, et al. A nested case-control study of metabolically defined body size phenotypes and risk of colorectal Cancer in the European prospective investigation into Cancer and nutrition (EPIC). PLoS Med. 2016;13:e1001988. https://doi.org/10.1371/journal.pmed.1001988.

13. Park YM, White AJ, Nichols $\mathrm{HB}$, et al. The association between metabolic health, obesity phenotype and the risk of breast cancer. Int J Cancer. 2017; 140:2657-66. https://doi.org/10.1002/ijc.30684.

14. Kuriyama S, Tsubono $Y$, Hozawa A, et al. Obesity and risk of cancer in Japan. Int J Cancer. 2005;113:148-57. https://doi.org/10.1002/ijc.20529.

15. Tanaka T, Nagata C, Oba S, et al. Prospective cohort study of body mass index in adolescence and death from stomach cancer in Japan. Cancer Sci. 2007;98:1785-9. https://doi.org/10.1111/j.1349-7006.2007.00583.x.

16. Li F, Du H, Li S, Liu J. The association between metabolic syndrome and gastric Cancer in Chinese. Front Oncol. 2018;8:326. https://doi.org/10.3389/ fonc.2018.00326.

17. Yoo H, Kim H, Lee JH, et al. Study on the relevance of metabolic syndrome and incidence of gastric Cancer in Korea. Int J Environ Res Public Health. 2019;16:1101. https://doi.org/10.3390/ijerph16071101

18. Li Z, Han H, Chang Y. Association between metabolic syndrome and the incidence of gastric cancer: a meta-analysis of cohort studies. Diabetol Metab Syndr. 2019;11:83. https://doi.org/10.1186/s13098-019-0478-y.

19. Lin $Y$, Ness-Jensen $E$, Hveem K, et al. Metabolic syndrome and esophageal and gastric cancer. Cancer Causes Control. 2015;26:1825-34. https://doi.org/ 10.1007/s10552-015-0675-4.

20. Hamaguchi M, Kojima T, Takeda N, et al. The metabolic syndrome as a predictor of nonalcoholic fatty liver disease. Ann Intern Med. 2005;143:7228.

21. Hashimoto $Y$, Hamaguchi M, Nakanishi $N$, et al. Urinary $\mathrm{pH}$ is a predicotr of diaetes in men; a population based large scale cohort study. Diabetes Res Clin Pract. 2017;130:9-14. https://doi.org/10.1016/j.diabres.2017.04.023.

22. Cigarette smoking and health. American Thoracic Society. Am J Respir Crit Care Med. 1996;153:861-5. https://doi.org/10.1164/ajrccm.153.2.8564146.

23. Aaron DJ, Kriska AM, Dearwater SR, et al. Reproducibility and validity of an epidemiologic questionnaire to assess past year physical activity in adolescents. Am J Epidemiol. 1995;142:191-201.

24. Hamaguchi M, Hashimoto Y, Obora A, et al. Non-alcoholic fatty liver disease with obesity as an independent predictor for incident gastric and colorectal cancer: a population-based longitudinal study. BMJ Open Gastroenterol. 2019;6:e000295. https://doi.org/10.1136/bmjgast-2019-000295.

25. World Health Organization Western Pacific Region, International Association for the Study of obesity/international obesity task force: the Asia-Pacific perspective: redefining obesity and its treatment, Melbourne, Australia, Health Communications Australia, 2000.

26. Okamura T, Hashimoto $Y$, Hamaguchi M, et al. Ectopic fat obesity presents the greatest risk for incident type 2 diabetes: a population-based longitudinal study. Int J Obes. 2019;43:139-48. https://doi.org/10.1038/ s41366-018-0076-3.

27. Hashimoto $Y$, Hamaguchi M, Tanaka M, et al. Metabolically healthy obesity without fatty liver and risk of incident type 2 diabetes: a meta-analysis of prospective cohort studies. Obes Res Clin Pract. 2018;12:4-15. https://doi. org/10.1016/j.orcp.2017.12.003.

28. Heianza Y, Kato K, Kodama S, et al. Stability and changes in metabolically healthy overweight or obesity and risk of future diabetes: Niigata wellness study. Obesity (Silver Spring). 2014;22:2420-5. https:// doi.org/10.1002/oby.20855.

29. Tramacere I, Negri E, Pelucchi C, et al. A meta-analysis on alcohol drinking and gastric cancer risk. Ann Oncol. 2012;23:28-36. https://doi.org/10.1093/ annonc/mdr135.

30. Nishino $Y$, Inoue $M$, Tsuji I, et al. Tobacco smoking and gastric cancer risk: an evaluation based on a systematic review of epidemiologic evidence 
among the Japanese population. Jpn J Clin Oncol. 2006;36:800-7. https:// doi.org/10.1093/jjco/hyl112.

31. Abioye Al, Odesanya MO, Abioye Al, et al. Physical activity and risk of gastric cancer: a meta-analysis of observational studies. Br J Sports Med. 2015;49: 224-9. https://doi.org/10.1136/bjsports-2013-092778.

32. Moore LL, Chadid S, Singer MR, et al. Metabolic health reduces risk of obesity-related cancer in Framingham study adults. Cancer Epidemiol Biomark Prev. 2014;23:2057-65. https://doi.org/10.1158/1055-9965.EPI14-0240.

33. Zhang ZF, Kurtz RC, Sun M, et al. Adenocarcinomas of the esophagus and gastric cardia: medical conditions, tobacco, alcohol, and socioeconomic factors. Cancer Epidemiol Biomark Prev. 1996;5:761-8.

34. Yoon JM, Son KY, Eom CS, Durrance D, Park SM. Pre-existing diabetes mellitus increases the risk of gastric cancer: a meta-analysis. World J Gastroenterol. 2013;19:936-45. https://doi.org/10.3748/wjg.v19.6.936.

35. Alemán JO, Eusebi LH, Ricciardiello L, et al. Mechanisms of obesity-induced gastrointestinal neoplasia. Gastroenterology. 2014;146:357-73. https://doi. org/10.1053/j.gastro.2013.11.051.

36. Pollak $M$ The insulin and insulin-like growth factor receptor family in neoplasia: an update. Nat Rev Cancer 2012;12:159-169. Published 2012 Feb 16. doi:https://doi.org/10.1038/nrc3215

37. Kuroda T, Kitadai Y, Tanaka S, et al. Monocyte chemoattractant protein-1 transfection induces angiogenesis and tumorigenesis of gastric carcinoma in nude mice via macrophage recruitment. Clin Cancer Res. 2005;11:762936. https://doi.org/10.1158/1078-0432.CCR-05-0798.

38. Ferder L, Inserra F, Martínez-Maldonado M. Inflammation and the metabolic syndrome: role of angiotensin II and oxidative stress. Curr Hypertens Rep. 2006;8:191-8. https://doi.org/10.1007/s11906-006-0050-7.

39. Gallagher EJ, LeRoith D. Minireview: IGF, insulin, and Cancer. Endocrinology. 2011;152:2546-51. https://doi.org/10.1007/s00125-016-4101-6.

40. Bañuls C, Rovira-Llopis S, Lopez-Domenech S, et al. Oxidative and endoplasmic reticulum stress is impaired in leukocytes from metabolically unhealthy vs healthy obese individuals. Int J Obes. 2017:41:1556-63. https:// doi.org/10.1038/ijo.2017.147.

41. Sesti G, Succurro E, Arturi F, et al. IGF-1 levels link estimated glomerular filtration rate to insulin resistance in obesity: a study in obese, but metabolically healthy, subjects and obese, insulin-resistant subjects. Nutr Metab Cardiovasc Dis. 2011;21:933-40. https://doi.org/10.1016/j.numecd. 2010.02.008.

42. Lee YC, Chiang TH, Chou CK, et al. Association Between Helicobacter pylor Eradication and Gastric Cancer Incidence: A Systematic Review and Metaanalysis. Gastroenterology. 2016;150:1113-1124.e5. https://doi.org/10.1053/j. gastro.2016.01.028

43. Inoue M. Changing epidemiology of helicobacter pylori in Japan. Gastric Cancer. 2017;20:3-7. https://doi.org/10.1007/s10120-016-0658-5.

\section{Publisher's Note}

Springer Nature remains neutral with regard to jurisdictional claims in published maps and institutional affiliations.

Ready to submit your research? Choose BMC and benefit from:

- fast, convenient online submission

- thorough peer review by experienced researchers in your field

- rapid publication on acceptance

- support for research data, including large and complex data types

- gold Open Access which fosters wider collaboration and increased citations

- maximum visibility for your research: over $100 \mathrm{M}$ website views per year

At $\mathrm{BMC}$, research is always in progress.

Learn more biomedcentral.com/submissions 